\title{
CENOGRAFIA E ETHOS DISCURSIVO NA "EMPRESA DOS SONHOS DOS EXECUTIVOS”: IMAGEM CORPORATIVA E CULTURA ORGANIZACIONAL
}

\author{
SCENERY AND ETHOS DISCURSIVE IN AN "COMPANY OF DREAMS FOR EXECUTIVES": \\ CORPORATE IMAGE AND ORGANIZATIONAL CULTURE
}

\author{
ESCENOGRAFÍA Y ETHOS DISCURSIVO EN UNA "EMPRESA DE LOS SUEÑOS DE LOS \\ EJECUTIVOS": IMAGEN CORPORATIVA Y CULTURA ORGANIZACIONAL
}

\author{
Andre Luciano Viana \\ Mestre, FEEVALE \\ andreviana@feevale.br \\ Ernani Cesar de Freitas \\ Dr, FEEVALE \\ ernanic@feevale.br
}

\begin{abstract}
Resumo: $\mathrm{O}$ artigo tem o objetivo geral é analisar o discurso a respeito da empresa Petrobras, manifestado no texto jornalístico, que possibilita construir cenografias das quais emergem evidências do ethos empresarial no discursivo corporativo. $\mathrm{O}$ marco teórico pautou-se em algumas categorias teóricas como: cultura (HALL, 2006; CANCLINI, 1998, 2004, 2010); cultura organizacional (SCHEIN, 2009; MORGAN, 1996) e mundialização (ORTIZ, 1997, 2007), na interface com pressupostos da análise do discurso da escola francesa (MAINGUENEAU 1997, 2002, 2008a, 2008b, 2008c, 2010, 2011). Os resultados apontam que o ethos discursivo corporativo é validado em cenografias que contribuem para a caracterização da imagem de pujança corporativa da empresa Petrobras.
\end{abstract}

Palavras-chave: Cultura Organizacional. Discurso. Cenografia. Ethos.

\begin{abstract}
The theme of this article is the study on the reporting of Exame "Petrobras, the dream's company of executives" and shows the overlapping concepts of culture, organizational culture and globalization. The overall goal is to analyze the discourse about the company Petrobras, expressed in the text, which allows to build sceneries including evidence emerging entrepreneurial ethos in corporate discourse. The theoretical framework was based on some theoretical categories such as culture (Hall, 2006; Canclini, 1998, 2004, 2010), organizational culture (SCHEIN, 2009; MORGAN, 1996) and globalization (ORTIZ, 1997, 2007), the interface with assumptions of discourse analysis of the French school (MAINGUENEAU 1997, 2002, 2008 a 2008b, 2008c, 2010, 2011). The results show that the corporate ethos discourse is validated sceneries that contribute to the characterization of the strength of corporate image of company Petrobras.
\end{abstract}

Key-Words: Organizational Culture. Discourse. Scenery. Ethos.

Resumen: El tema de este artículo es el estudio de la comunicación de Exame "Petrobras, la compañia de los sueños de los ejecutivos", y muestra los conceptos de superposición de la cultura, la cultura de la organización y la globalización. El objetivo general es analizar el discurso sobre la empresa Petrobras, expresado en el texto, lo que permite construir escenarios, incluyendo el ethos corporativo en el discurso corporativo. El marco teórico se basó en algunas categorías teóricas como la cultura (Hall, 2006; Canclini, 1998, 2004, 2010), la cultura organizacional (Schein, 2009; MORGAN, 1996) y la globalización (Ortiz, 1997, 2007), la interfaz con supuestos del análisis del discurso de la escuela Francesa (Maingueneau 1997, 2002, 2008a, 2008b, 2008c, 2010, 2011). Los resultados muestran que el discurso ethos corporativo contribui a la caracterización de la fuerza de la imagen corporativa de la empresa Petrobras.

Palabras -clave: Cultura Organizacional. Discurso. Escenografía. Ethos.

Esta obra está licenciada sob uma Licença Creative Commons 


\section{Introdução}

Mediante os diferentes tipos de linguagens, muitas vezes, a relação entre aquilo que é global e aquilo que é local é movida por perspectivas de distintas inter-relações. Entretanto, esta forma de relação nem sempre é comum, direta e perspicaz, principalmente no que tange à imagem que as pessoas e organizações fazem de si em suas relações com os outros. Dessa forma, a cultura incute nas organizações suas crenças e valores e relaciona-se diretamente com os anseios corporativos em um ambiente cujas mudanças são eminentes. A fim de analisar estas relações, o tema desta pesquisa compreende os estudos sobre a cultura e a cultura organizacional e serão abordadas as principais características do ethos discursivo como imagem de si, demonstradas na cultura organizacional de uma empresa brasileira internacionalizada, e analisadas por meio dos planos constitutivos do discurso que integram a Semântica Global (MAINGUENEAU, 2008a)

O texto escolhido para a análise trata-se da reportagem da Revista Exame, edição 1008, de 25 de janeiro de 2012, cujo título é "Petrobras, a empresa dos sonhos dos executivos" e justificase sua escolha pela relevância que a relação entre a cultura e a cultura organizacional tem para o ambiente corporativo, principalmente em uma empresa de importância para o mercado brasileiro. Logo, a questão norteadora de pesquisa é a seguinte: como se apresentam os discursos que contribuem à concepção do ethos discursivo corporativo da empresa Petrobras, correlacionados entre cultura, cultura organizacional e mundialização?

Desse modo, o objetivo geral tem como ênfase analisar a constituição do discurso corporativo de uma empresa brasileira internacionalizada, que contribui à concepção do ethos discursivo corporativo correlacionando-se cultura, cultura organizacional e mundialização. Também se faz necessário conhecer os objetivos específicos, como: a) identificar a relação existente entre cultura e cultura organizacional; b) descrever a construção do ethos discursivo corporativo como imagem de si, por meio da cenografia amparada nos estereótipos e clichês de uma empresa internacionalizada em um contexto mundializado.

Neste artigo, o diálogo está centrado na construção de uma imagem de si - ethos corporativo - das empresas internacionais, que se reflete de fora (da sociedade) para dentro (para a cultura organizacional).

\section{A cultura e a construção da realidade organizaconal}

Muitas vezes, os valores originados pelas organizações trazem consigo estereótipos que alicerçam as ações corporativas, a fim de competir com o "progresso tecnológico"; a "eficácia empresarial"; a "modernização"; o "crescimento econômico", correlacionando-se com a cultura da 
sociedade em que a empresa está inserida. Assim, apesar de o termo "cultura" ser apresentado com certa frequência nos últimos anos, em relação às divulgações nas mais diversas mídias, seu significado ainda necessita de definições muito mais profundas, quanto ao seu real simbolismo na vida de cada região e grupos sociais. Ao ser pesquisado por Tyler em 1871, citado por Laraia, (2001), o conceito relacionado à cultura também pode ter o significado de um estudo sistemático, pois trata-se de um fenômeno natural que possui causas e regularidades, permitindo um estudo objetivo e uma análise capazes de proporcionar a formação de leis sobre o processo cultural e também sua evolução.

As empresas que se manifestam, em seus discursos, como atuantes no mercado internacional, revelam as relações entre cultura e sociedade e, assim, impelem também às empresas determinados atributos que contribuem para a formação de sua cultura organizacional.

Da mesma forma, tanto Hall (2006) quanto Laraia (2001) concordam em afirmar que a cultura e a identidade são realmente formadas ao longo do tempo, através de processos quase que inconscientes de uma sociedade, ou seja, uma tradição. A cultura também é linguagem, faz parte de um constructo coletivo, no qual este ato de linguagem se manifesta (CHARAUDEAU, 2009). Ao mesmo tempo, Barthes (2004) destaca que o discurso precisa de detalhes para seu convencimento, cujo preenchimento dos espaços vazios na comunicação permite a criação de um contexto. Desta forma, através dos conceitos apresentados pelos autores, pode-se identificar a importância desses ensinamentos na cultura e suas manifestações, também refletidos no ambiente organizacional.

Desse modo, percebe-se que a grande volatilidade de informações que são trazidas todos os dias pelos mais diversos meios de comunicação e, com as mais diferentes intencionalidades, influenciam a vida de cada cidadão e, assim, corroboram para a construção de novas identidades.

Em relação à cultura organizacional, esta cultura, que vem do coletivo, traz uma herança, um conhecimento, por meio de linguagens que envolvem o receptor e o emissor. Trata-se de códigos e de fenômenos, como algo que se expõe, que aparece, e sua interpretação tem o objetivo de transmitir compreensões com linguagem adequada. Assim, percebe-se uma relação densa entre o conceito de cultura e o conceito de fazer efetivamente algo, também aparente na cultura organizacional. Outro motivo de reflexão é pensar que a cultura, independente se é japonesa, árabe, inglesa, canadense, francesa ou americana, de fato, define o caráter da organização (MORGAN, 1996).

Assim como a globalização poderá provocar mudanças nas identidades culturais (HALL, 2006), também tais mudanças são refletidas no ambiente organizacional, pois, segundo Morgan (1996, p.116), 
[...] Ao falar-se de cultura, refere-se tipicamente ao padrão de desenvolvimento refletido nos sistemas sociais de conhecimento, ideologia, valores, leis e rituais quotidianos. A palavra é também habitualmente usada para fazer referência ao grau de refinamento evidente em tais sistemas de crenças e práticas.

Em decorrência deste enfoque, pode-se perceber que a cultura gera resultados distintos, mas que imbuídos de um contexto social, possibilitam a criação de um ethos corporativo que revela uma densa relação entre "o dito" e o "mostrado". Também se percebe que a cultura da organização desenvolve um ethos, criado e desenvolvido pelos processos sociais, as imagens, os símbolos e os rituais que existem dentro das organizações (MORGAN, 1996).

Aqui, então, volta-se a tratar da cultura de um grupo, que poderá ser definida como um padrão de suposições básicas compartilhadas, que uma vez alcançado será considerado válido e, por conseguinte, ensinado aos novos membros como o modo correto de perceber, pensar e sentirse em relação a essas suposições (SCHEIN, 2009).

Nesta linha de pensamento, essa relação entre cultura e cultura organizacional apresenta de forma mais efetiva a construção das identidades corporativas (imagens de si), principalmente ao refletir sobre os contextos de mundialização atualmente vivenciados, e podem ser estudadas por meio da semântica global e os planos constitutivos dos discursos, descritos na seção seguinte.

\section{Por uma semântica global: os planos constitutivos do discurso}

Maingueneau (2008a), ao tratar sobre semântica global, propõe uma metodologia que possibilita a análise dos discursos por meio dos planos constitutivos do discurso, conforme revelam-se a seguir:

- A intertextualidade caracteriza-se pelo tipo de relações definidas como legítimas pelas coerções semânticas, ou seja, pela competência discursiva em um determinado campo, pois "todo campo discursivo define uma certa maneira de citar os discursos anteriores de um mesmo campo, e cada discurso constrói para si um passado específico, atribui-se certas filiações e recusa outras. O sistema de coerções intervém nesses dois níveis de intertextualidade" (SOUZA-ESILVA; ROCHA, 2009, p. 4).

- As questões em torno da significação e do tema estão relacionadas a certos problemas de compreensão, o que conjectura uma forma de diálogo para a teoria Bakhtiniana, pois, neste processo responsivo ativo, é essencial reconhecer o tema na relação com a significação, sem dar a ele preferência no que se refere à vinculação a um sentido sempre estável e idêntico a si mesmo (ZAGO; DI FANTI, 2008). É importante ressaltar comentário de Maingueneau (2008a): 
por definição, os temas, que não são impostos pelo campo discursivo podem estar ausentes de um discurso, mas aqueles, que são impostos, podem estar presentes de formas muito variadas.

- $\quad$ Outro dado tem relação ao vocabulário, que se trata de um campo constituinte da semântica global. Mesmo considerando que o vocabulário em si não é um objeto que tenha notoriedade na análise de um discurso, pois esta concepção seria minimizar a intensidade de um discurso frente às informações que pretende comunicar, fica improvável dizer que um discurso possua um léxico que lhe fosse próprio, pois a palavra em si mesma não constitui uma unidade de análise pertinente (MAINGUENEAU, 2008a), entretanto, "em contrassenso, seria errado pensar que, em um discurso, as palavras não são empregadas a não ser em razão de suas virtualidades de sentido em língua” (MAINGUENEAU, 2008a, p. 81).

- Poder-se-ía então dizer que "em termos de discurso, tanto o enunciador quanto o destinatário dispõem de um lugar e, nesse espaço, o enunciador projeta uma imagem de si no discurso a partir da qual o legitima" (FREITAS; FACIN, 2011, p. 5). Partindo do princípio que todos os planos do discurso, inclusive o modo de enunciação, o estatuto do enunciador e do destinatário compõe esse quadro cênico no qual este enunciador se inscreve, são regidos por uma mesma semântica e não há, portanto, hierarquia de lugares de análise, pois tudo converge para um mesmo funcionamento semântico-discursivo (SILVA, 2006).

- $\quad$ Pode-se afirmar que na língua, segundo Maingueneau (1997), a dêixis estabelece as coordenadas espaço-temporais implicadas em um ato de enunciação, ou seja, trata-se do conjunto de referências articuladas Ainda nesse contexto, torna-se importante ressaltar que o modo de enunciação define as características necessárias para que a comunicação aconteça e, nesse sentido, pode-se dizer que associado ao estatuto de enunciador e destinatário, esse discurso comporta determinadas marcas as quais o situam no espaço e no tempo: fala-se da dêixis enunciativa (FREITAS; FACIN, 2011).

Amossy (2008b, p.126) complementa, afirmando que

$$
\begin{aligned}
& \text { a estereotipagem, lembremos, é a operação que consiste em pensar o real por meio de } \\
& \text { uma representação cultural preexistente, um esquema coletivo cristalizado. Assim, a } \\
& \text { comunidade, avalia e percebe o indivíduo segundo um modelo pré-construído da } \\
& \text { categoria por ela difundida e no interior da qual ela o classifica. Se se tratar de uma } \\
& \text { personalidade conhecida, ele será percebido por meio da imagem pública forjada pelas } \\
& \text { mídias. As práticas sociológicas e semiológicas definem geralmente o estereótipo tem } \\
& \text { tempo de atribuição [...]. }
\end{aligned}
$$

Isto se confirma quando, como exemplo, cita-se o discurso publicitário contemporâneo, esse mantém, por natureza, uma estreita relação com o ethos e procura persuadir, associando os produtos que promove a um corpo em movimento, a uma maneira de habitar o mundo; como um 
discurso religioso, em particular, é por meio de sua própria enunciação que uma propaganda, apoiando-se em estereótipos pré-avaliados, deve encarnar o que o discurso prescreve (MAINGUENEAU, 2008b). Esses exemplos revelam como o discurso pode estar associado a um fiador que remete determinada confiabilidade sobre um contexto e, assim, revela um modo de encadeamento, também chamado de modo de coesão.

- $\quad$ Pode-se considerar que o modo de coesão tem a ver com a maneira pela qual um discurso solidifica suas remissões internas, o que remete à teoria da anáfora discursiva e recobre fenômenos muito diversos, entre eles o recorte discursivo exerce-se num nível fundamental, que atravessa as divisões em gêneros constituídos (SOUZA-E-SILVA; ROCHA, 2009).

Os autores pesquisados corroboram que o conceito de semântica global, apresentado por Maingueneau (2008a), não consiste em privilegiar um plano discurso e excluir outro; em realidade, o conceito de "global" envolve o encontro de todos os planos como essenciais à construção da cenografia.

Amossy (2008a) declara que todo ato de tomar a palavra implica a construção de uma imagem de si. Para tanto, não é necessário que o locutor faça seu autorretrato, detalhe suas qualidades, nem mesmo que fale explicitamente de si. Seu estilo, suas competências linguísticas e enciclopédicas, suas crenças implícitas são suficientes para construir uma representação de sua pessoa.

De acordo com Maingueneau (2002), tomar a palavra significa, em graus variados, assumir um risco; a cenografia não é simplesmente um quadro, um cenário, como se o discurso aparecesse inesperadamente no interior de um espaço já construído e independente dele: é a enunciação que, ao se desenvolver, esforça-se para construir progressivamente a seu próprio dispositivo de fala.

Considera-se que por meio do ethos, o destinatário - receptor da informação - está, com certeza, convocado a um lugar inscrito na cena de enunciação que o texto implica, pode-se considerar que há a incorporação de três cenas, mencionadas por Maingueneau (1997) e ratificadas por esse linguista (MAINGUENEAU, 2008b): a cena englobante, que atribui ao discurso um estatuto pragmático, ela o integra em um tipo: publicitário, administrativo, filosófico, etc; a cena genérica é a do contrato associado a um gênero ou a um subgênero do discurso: o editorial, o sermão, o guia turístico ou a consulta médica; a cenografia não é imposta pelo gênero, mas construída pelo próprio texto: um sermão pode ser enunciado por meio de uma cenografia professoral, profética, amigável, etc. Esta cenografia é a cena de fala que o discurso pressupõe para poder ser enunciado e que, por sua vez, deve validar através da sua própria enunciação: em qualquer discurso, por seu próprio desenvolvimento, pretende instituir a situação de enunciação que o torna pertinente. 
O modo como se faz a apresentação de si, através do ethos, é parte central do debate público, da negociação empresarial e ainda participa dos diálogos entre professor e alunos, das reuniões de condôminos, da conversa entre amigos ou da relação amorosa (AMOSSY, 2008a). Essa cenografia pode representar também uma relação entre a imagem que as empresas internacionais fazem de si - ethos - aparente nos discursos jornalísticos.

Adam (2008, p. 96) comenta que "qualquer "atividade discursiva" origina uma esquematização, remetendo esse último termo tanto a um processo quanto a um resultado". Assim, definir o objeto da análise de discurso menos como um enunciado, um texto, ou um discurso do que como uma esquematização discursiva é, deliberadamente, reunir, em um mesmo termo, a enunciação como processo e o enunciado como resultado (ADAM, 2008).

Dessa forma, configura-se que o enunciador deve legitimar seu dizer: em seu discurso, o enunciador se atribui uma posição institucional e marca sua relação a um saber. No entanto, ele não se manifesta somente como um papel e um estatuto, o enunciador deixa-se aprender também como uma voz e um corpo. O ethos se traduz também no tom, que se relaciona tanto ao escrito quanto ao falado, e que se apoia em uma "dupla figura do enunciador", aquela de um caráter e de uma corporalidade, conforme apontam Charaudeau e Maingueneau (2008) ao retomarem Maingueneau (1984, p. 100).

A partir das literaturas pesquisadas até o momento, ao refletir sobre a linguagem em cenários relacionados ao ambiente de trabalho, apresentam-se dificuldades e especificidades, sendo necessária a interação com outras áreas do conhecimento. Desse modo, após o diálogo entre os variados conceitos de análise do discurso, de cenografia e de ethos discursivo, a seguir apresenta-se a metodologia utilizada nesta pesquisa.

\section{Metodologia}

Considera-se que a pesquisa, sob o ponto de vista de seus objetivos, caracteriza-se como descritiva. Sob o ponto de vista dos procedimentos técnicos, o estudo é considerado como pesquisa bibliográfica. Nesse sentido, considerando que há um vínculo indissociável entre o ambiente objetivo e o sujeito subjetivo, aplicou-se uma abordagem qualitativa para esclarecimento do problema de pesquisa, pois "na análise dos dados coletados, não há preocupação em comprovar hipóteses previamente estabelecidas, porém estas não eliminam a existência de um quadro teórico que direcione a coleta, a análise e a interpretação dos dados" (PRODANOV; FREITAS, 2009, p. 81). Utilizou-se como suporte a análise do discurso, de vertente francesa e base enunciativa para análise da comunicação e da interação verbal nas reportagens, visto que, segundo Chizzotti (2010, p. 113), "constitui-se como um tipo de análise que ultrapassa os aspectos meramente formais da linguística, para privilegiar a função e o processo da língua no contexto interativo e social [...]”. 
A análise de discurso é amparada por categorias teóricas segundo os estudos sobre cenografia e ethos, de Dominique Maingueneau (1997, 2002, 2008a, 2008b, 2008c, 2010, 2011) a partir dos princípios gerais da semântica global, conforme mencionados na seção 3 .

\section{Resultados e análise : a imagem de uma empresa brasileira internacionalizada}

Primeiramente, apresenta-se uma síntese descritiva do texto jornalístico; logo após, mediante fragmentos do texto, identifica-se a relação entre duas categorias inter-relacionadas: cultura e cultura organizacional, todas manifestadas pelo enunciador a um coenunciador/destinatário na construção de cenografias que instituem o ethos discursivo corporativo exposto na reportagem analisada.

\section{Reportagem "petrobras, a empresa dos sonhos dos executivos"}

A reportagem descreve dados de uma pesquisa realizada em 2011 por consultorias da área de Recursos Humanos, que elegeram a estatal Petrobras, como sendo a empresa na qual os executivos brasileiros mais gostariam de trabalhar. Fatores como estabilidade, possibilidade de crescimento e investimento na carreira profissional são atrativos demonstrados pela empresa na reportagem publicada pela Revista Exame de 28/01/2012, com autoria do jornalista Lucas Amorim (2012). O texto também critica de forma breve a relação entre os brasileiros e os concursos públicos e que o objetivo principal dos executivos brasileiros entrevistados é, em realidade, a estabilidade e a procura pelo o que o enunciador-jornalista chama de "O que eu quero é sossego", ao comparar o processo de gestão da Petrobras com o de outras empresas internacionalizadas, como: Ambev, Google, Vale e Itaú. Dessa forma, a imagem de credibilidade que esta revista atesta às suas reportagens já pressupõe, em grande medida, a aprovação de seu público leitor.

$\mathrm{Na}$ primeira categoria de análise, serão apresentados e identificados os elementos constitutivos relacionados com a cultura, analisados no texto jornalístico. Nesse sentido, percebese que o primeiro artifício que chama a atenção do leitor ao texto é o próprio subtítulo da reportagem:

Fragmento 1: Uma pesquisa exclusiva revela que a Petrobras é a empresa dos sonhos dos executivos no Brasil. A receita: crescimento, investimento em formação - e, claro, muita estabilidade.

Na sociedade atual, a cultura é pautada pelas manifestações culturais, pelas relações entre as pessoas e também pelo consumo, sendo que este terceiro indicador aqui relatado é possível de 
ser mensurado através do mundo do trabalho, no qual as pessoas recebem seu salário e, dessa forma, almejam uma carreira promissora com o intuito de atingir seus objetivos profissionais e pessoais. Essa cultura, para Barthes (2004), encontra-se nas mais diversas formas de manifestações, seja em produtos, na imagem ou na linguagem, estando em toda a parte, ou seja, em todos os contextos sociais. Nesse sentido, o enunciador-jornalista cria certa expectativa de "empresa ideal" ao leitor, pois levando em consideração que a Revista Exame é fiador de um público específico [os executivos brasileiros], a chamada "empresa dos sonhos" é caracterizada pela organização capaz de satisfazer aos anseios profissionais de qualquer executivo leitor desse periódico. Este modo de enunciação, que "não é somente determinado conteúdo associado a uma dêixis e a um estatuto de enunciador e de destinatário, é também uma "maneira de dizer" específica" (MAINGUENEAU, 2008a, p. 90), pois caracteriza a intertextualidade presente no texto, com características da área de gestão de pessoas, cuja importância é veemente no processo de uma empresa que deseja ser considerada como uma referência frente às demais instituições. Também se pode considerar que o leitor perceba que o discurso nesse texto está imbuído de uma coerência global, que integra muitas dimensões textuais (MAINGUENEAU, 2008a).

Em relação ao tema e ao vocabulário, essa mesma expressão “empresa dos sonhos” eleva a organização à categoria de algo ilusório, irreal, mas acessível aos interesses dos profissionais que lá estiverem. Há, principalmente, uma aproximação com as expectativas do estereótipo cultural de "bom profissional" arrolado pelos valores da sociedade, a qual preza que as pessoas tenham um trabalho justo e bem remunerado e, finalmente, uma expectativa de valorização contida na reportagem pela expressão que denota o sucesso da organização, composto de “crescimento, investimento em formação - e, notoriamente, muita estabilidade".

Com base em Barthes (2004), verifica-se a forma como o texto descreve a empresa, pois esse autor destaca que o discurso precisa de detalhes para seu convencimento e este atributo de convencimento é utilizado no texto jornalístico. A Petrobras é uma empresa pública e a expressão "e, claro, muita estabilidade", significa, nesse contexto discursivo, uma aproximação com a cultura brasileira de profissionalização em empregos públicos, em que a estabilidade é um ideal perseguido pelos candidatos a estas vagas.

Esses discursos revelam características de uma sociedade e, mesmo em um cenário mundializado no qual a mudança é constante, tanto Hall (2006) quando Laraia (2001) convergem ao afirmarem que a cultura e a identidade são realmente formadas ao longo do tempo, através de processos quase que inconscientes de uma sociedade. Há ainda, o fragmento a seguir:

Fragmento 2: O objetivo, claro, é garantir emprego para a vida toda, aposentadoria 
pública e, de preferência, uma vida mais distante das crescentes pressões corporativas. Se o brasileiro médio sonha com esse jeito concursado de ser, como pensam nossos executivos? [...]

Esse "tom”, essa “vocalidade", utilizado no modo de enunciação do segmento demonstrado acima permite uma representação do estatuto do enunciador e do destinatário, e revela que "os diversos modos da subjetividade enunciativa dependem igualmente da competência discursiva, sendo que cada discurso define o estatuto que o enunciador deve se atribuir e o que deve atribuir a seu destinatário para legitimar seu dizer" (MAINGUENEAU, 2008a, p. 87), visto que apresenta a construção de uma cenografia impelida ao profissional, brasileiro, que busca a estabilidade através da carreira pública, no qual o enunciador [EU=fiador] que se instaura na enunciação do discurso para persuadir o destinatário [TU] no sentido de demonstrar que o trabalho em uma empresa pública dá garantias de estabilidade infindável.

Esses fragmentos discursivos destacados anteriormente também reforçam e instauram a criação de estereótipos culturais que são confirmados pelo modo de coesão, que as ideias foram harmonizadas, pois no Fragmento 2, ao relatar "garantir emprego para a vida toda" e ainda "uma vida mais distante das crescentes pressões corporativas", revela-se um modo de viver, de um profissional que pretende ter uma vida profissional menos estressante e mais estabilizada, pois todo ato de tomar a palavra implica na representação de uma imagem de si (AMOSSY, 2008a).

Os estereótipos culturais, que segundo Amossy (2008b, p. 126), são revelados por meio da "operação que consiste em pensar o real por meio de uma representação cultural preexistente, um esquema coletivo cristalizado" também se evidenciam nesses fragmentos analisados, pois se observa a estereotipagem da "empresa perfeita" [Petrobras = oferece investimento, crescimento e estabilidade] e do "executivo brasileiro sossegado"[executivo brasileiro que prefere o concurso público às pressões da vida corporativa]. O fiador [Revista Exame], por meio de seu "tom", atesta o que é dito (MAINGUENEAU, 2008b), apresenta nesses excertos de discurso analisados que a empresa Petrobras está relacionada ao estereótipo de empresa ideal, um desejo que poderia ser elencado por muitos executivos, dessa forma, revelando a identidade da empresa produtiva, em permanente crescimento e desenvolvimento econômico-financeiro, por isso seria "a empresa dos sonhos dos executivos".

A relação entre o ethos dito revela-se como uma empresa que se apresenta diante de um mundo corporativo eficaz, adequado a qualquer profissional. Em relação ao ethos mostrado, traz a cenografia que corresponde a essa apresentação. Até esse momento, na categoria cultura, este ethos discursivo corporativo revela-se como constituinte de uma empresa sólida, estável e garantidora do bem-estar profissional de qualquer executivo que passe a integrar o quadro 
funcional da empresa.

Na sequência, destaca-se a segunda categoria de análise: cultura organizacional. Percebe-se que o texto jornalístico também revela a cultura organizacional da corporação Petrobras, que pode ser identificada em diversos segmentos discursivos da reportagem. Inicialmente, analisa-se o Fragmento 3:

Fragmento 3: Eis, resumidamente, a carreira que nossos executivos querem ter. Primeiro, é preciso estudar um bocado para passar em concursos públicos que chegam a ter 1.000 candidatos para cada vaga. Quem passa no concurso fica 8 horas por dia, durante até um ano, em treinamento sobre temas como geologia, dinâmica dos solos e extração de petróleo.

Nesse segmento, manifesta-se em primeiro plano que o enunciador-jornalista se dirige diretamente ao destinatário [executivos brasileiros] através do tema e do vocabulário utilizados, pois ao dizer "Eis, resumidamente, a carreira que nossos executivos querem ter", apresenta um padrão de cultura organizacional que poderia sugerir uma empresa que tivesse um plano de carreira pré-definido e que, após determinados requisitos, há um objetivo comum no qual todos os executivos da empresa ambicionam e tendem a atingir [querem], que é a ascensão profissional. Assim, ao relatar sua cultura organizacional por meio de linguagens que envolvam o receptor e o emissor, a empresa define seu caráter (MORGAN, 1996), o que fica aparente nesse excerto discursivo analisado.

A dêixis-enunciativa revela que "o ato de enunciação supõe a instauração de uma "dêixis" espacio-temporal, que cada discurso constrói em função de seu próprio universo (MAINGUENEAU, 2008a, p. 88), que junto ao modo de enunciação demonstram-se no enunciado: "Primeiro, é preciso estudar um bocado para passar em concursos públicos que chegam a ter 1.000 candidatos para cada vaga", pois, dessa forma, visualiza-se aqui que há uma necessidade de esforço para formar determinadas competências a fim de que existam condições necessárias à latente competição dos concursos públicos brasileiros.

Além disso, esse trecho também centra-se na intertextualidade da atual situação do mercado de trabalho, que passa por um processo de profissionalização necessário devido ao elevado grau de concorrência entre candidatos. Esse relato nos faz relembrar Maingueneau (2008b), de que a incorporação do leitor ultrapassa a simples identificação a uma personagem fiadora, pois ela implica um "mundo ético" do qual o fiador é parte integrante e ao qual ele dá acesso. Nesse texto, a Revista Exame é o enunciador, caracterizado como fiador desse discurso, muitas vezes, representa ou simboliza o mercado de trabalho dos executivos brasileiros em suas reportagens. Também torna-se evidente a relação intertextual com outras áreas de estudo, como de treinamento e desenvolvimento de pessoas e também a geologia. 
No entanto, ao mesmo tempo em que esses segmentos estudados indicam os atributos da eficácia da cultura organizacional dessa instituição, os próximos trechos discursivos apresentam algumas evidências que incidem certo grau de influência externa no ambiente corporativo, tais como:

Fragmento 4: O passo seguinte é ir a campo, o que significa, em alguns casos, vestir um macacão alaranjado e passar semanas em alto-mar. Se tudo der certo, vem o convite para assumir um cargo executivo. Primeiro de coordenador, depois gerente, gerente executivo, diretor, presidente - no caminho, não custa lembrar que ter um bom padrinho no partido do governo será fundamental.

Verificamos no fragmento 4 uma relação com a dêixis enunciativa a partir do enunciado "O passo seguinte é ir a campo, o que significa, em alguns casos, vestir um macacão alaranjado e passar semanas em alto-mar", ou seja, quando o discurso comporta determinadas marcas as quais o situam no espaço e no tempo: fala-se da dêixis enunciativa (FREITAS; FACIN, 2011). Nesse sentido, a relação espaço-tempo se dá por meio de uma cenografia de um executivo-trabalhador, que, com o passar do tempo, coopera com a organização colocando, de fato, "mãos à obra" junto aos processos de trabalho da empresa. Maingueneau (2008b) comenta sobre os estereótipos culturais do mundo ético, neste caso dos executivos, que nesse trecho apresenta-se como parte do trabalho braçal, que demanda tempo e dedicação, de experiência pessoal com as tarefas, já que ao dizer "vestir um macacão alaranjado" é incorporar a personagem "trabalhador ideal". O vocabulário, o tema e o modo de enunciação desse texto acarretam uma imagem de empresa que se preocupa com a profissionalização e integração de sua equipe de trabalho, revelando uma intertextualidade com outras áreas, como treinamento e desenvolvimento e pedagogia empresarial.

Entre as categorias para descrever a cultura organizacional elaborada por Schein (2009) existe uma delas que aborda "as regras do jogo", que são regras implícitas, não escritas, mas difundidas por toda a organização e constituintes da maneira de como "as coisas" ocorrem nas empresas. Contudo, percebe-se que a cultura organizacional gera resultados distintos, mas que, imbuídos de um contexto social, possibilitam a criação de um ethos discursivo corporativo que revela uma densa relação entre "o dito" e o "mostrado, pois na finalização desse mesmo Fragmento 4, exibe-se a visão do enunciador-jornalista e apresenta um sinuoso contraponto ao que a empresa manifesta como igualdade: "no caminho [ascensão profissional], não custa lembrar que ter um bom padrinho no partido do governo será fundamental".

Esse argumento confirma a ocorrência da intertextualidade em direção a um estereótipo já tão divulgado, da cultura brasileira: revela a face obscura do "jeitinho brasileiro" que se expõe dentro da cultura organizacional, pois ao mesmo tempo em que o tema e o vocabulário permitem a 
intencionalidade da ascensão profissional através de esforço pessoal, também existe um modo de enunciação que dissimula benefícios especiais que estão além dos valores cabíveis a qualquer relação de trabalho, pois um auxílio externo [bom padrinho no partido do governo] auxiliaria no crescimento profissional, já que a empresa Petrobras é uma estatal brasileira e poderá deter esses subsídios em sua relação profissional.

Assim, a cenografia de uma "empresa dos sonhos dos executivos" continua manifestando-se no texto, agora sob o ponto de vista da mundialização. Ortiz (1997) comenta que atualmente tudo é muito desterritorializado, pois pessoas e produtos circulam quase que livremente por todo mundo, influenciando a cultura e o modo de vida da sociedade e, portanto, influenciam também na cultura organizacional. A empresa estudada também corrobora com essa afirmação, pois conforme exemplificado no Fragmento 5:

Fragmento 5: Para ter gente preparada, investiu 202 milhões de reais em treinamento nos últimos 12 meses e enviou 1.800 pessoas para programas de treinamento fora do país - em escolas de negócios como Harvard e Insead e em universidades especializadas em pesquisas de petróleo.

Podemos constatar, novamente, que a construção da imagem de si relacionada ao sentido de ser a "empresa dos sonhos" demonstra, reiteradamente, sua intertextualidade com o ambiente de gestão de pessoas, assim como já explanada na primeira (cultura) e segunda (cultura organizacional) categorias de análise. Ao investir em treinamentos, a Petrobras estaria confirmando a cenografia necessária para tais ações, pois considera necessário o processo de desterritorialização, enviando seus executivos para treinamento e desenvolvimento em universidades estrangeiras. O tema e o vocabulário usados, revelados no enunciado "202 milhões de reais em treinamento" ou ainda "escolas de negócios como Harvard e Insead" demonstram a pujança corporativa, pois a empresa Petrobras tem condições de realizar altos investimentos em cursos e treinamentos de seus funcionários, mesmo que fora do país, em universidades renomadas e reconhecidas internacionalmente [Harvard e Insead], apoiando-se na imagem de empresa ideal.

Percebemos, também, nesse fragmento discursivo o "tom" de persuasão, pois ao demonstrar em números o interesse pelo treinamento de seu pessoal, o texto representa/simboliza uma "imagem de si” - uma empresa preocupada com a formação profissional de seus funcionários, pois segundo (FREITAS; FACIN, 2011,p. 7, grifo do autor) “em consonância com a cenografia, todo discurso possui uma imagem, imagem esta que é construída por uma voz, um tom, um corpo próprio: eis a noção de ethos discursivo".

A cultura organizacional da Petrobras também é revelada pelo segmento que compara a 
empresa com outra companhia brasileira internacionalizada:

Fragmento 6: "Estamos crescendo muito e investindo pesado em formação de pessoas e tecnologia de ponta. É uma combinação que atrai”, diz José Sergio Gabrielli, presidente da Petrobras. A Vale, terceira colocada no ranking, frequenta os sonhos dos executivos por motivos parecidos.

Esse trecho revela que o estatuto do enunciador e destinatário vem pouco a pouco se construindo no decorrer da reportagem através do fiador [Revista Exame], pois em vários momentos verificamos como a empresa apresenta certa preocupação em relação à formação de seus colaboradores, e isso reflete na "combinação que atrai" candidatos às vagas dos concursos públicos da empresa Petrobras. Nesse mesmo Fragmento 6, constatamos uma intertextualidade revelada com a citação à empresa Vale, que é lembrada como a companhia que ficou no terceiro lugar no ranking referido pelo jornalistas e que tem atributos similares àqueles mencionados aos da Petrobras, pois "A Vale, terceira colocada no ranking, frequenta os sonhos dos executivos por motivos parecidos". Ou seja, o estatuto do enunciador e do destinatário, nesse momento, é percebido como $[E U=P E T R O B R A S]$ em uma comparação com $[T U=V A L E]$. Em ambos os casos, confrontando-se mutuamente pelo título de "empresa dos sonhos".

A seguir, apresentam-se as considerações finais desse estudo, expostos na seção seguinte.

\section{Considerações finais}

A relação entre cultura e cultura organizacional já fazem parte do contexto diário de cada indivíduo, seja na articulação entre as pessoas, o consumo ou as relações de trabalho. Nesse sentido, como possível resposta à questão norteadora de pesquisa, o resultado aponta que os discursos apresentam um plano discursivo que pode ser analisado através da semântica global que, nessas primeiras reflexões do estudo, revelaram uma densa relação entre a cultura externa e a cultura organizacional de uma empresa brasileira internacionalizada. Todos esses elementos discursivos contribuem à concepção do ethos discursivo corporativo de uma empresa brasileira internacionalizada, correlacionados entre cultura, cultura organizacional e mundialização.

Torna-se relevante ao estudo perceber que o processo de análise do discurso, mesmo exigindo um cuidadoso processo de reflexão, com a visão de sobreposição de importantes teóricos, como base em Dominique Maingueneau (1997, 2002, 2008a, 2008b, 2008c, 2010, 2011) 
demonstra o quanto é sinuoso o caminho da linguagem que é transmitida através da cenografia que compõe o ethos corporativo organizacional, sendo uma profunda e fugaz abertura de intencionalidades.

Também é importante destacar que, como proposta de continuidade de estudo e sua temática, poderia buscar-se compreender a criação do ethos corporativo organizacional de uma empresa internacionalizada e não brasileira, mas com atuação local, a fim de comparar se a origem da organização, sua cultura organizacional, influencia na construção de seu ethos corporativo institucional.

Assim, é possível compreender que a cultura tem relação profunda com a cultura organizacional e que o discurso corporativo organizacional constrói sua identidade pelo discurso, através de uma cenografia que lhe é própria ao modo de dizer.

\section{Referências}

ADAM, Jean-Michel. Imagens de si e esquematização do orador: Pétain e De Gaulle em junho de 1940. In: AMOSSY, Ruth. Imagens de si no discurso. São Paulo: Contexto, 2008, p. 93-118.

AMORIM, Lucas. Petrobras, a empresa dos sonhos dos executivos. Revista Exame. São Paulo. V. 1, n. 1008, 28 jan. 2012. Disponível em:< http://exame.abril.com.br/noticia/mais-segurancamenos-ambicao/imprimir>. Acesso em: 28 jan. 2012.

AMOSSY, Ruth (Org.). Imagens de si no discurso.São Paulo: Contexto, 2008a.

. O ethos na intersecção das disciplinas. In: AMOSSY, Ruth (Org.). Imagens de si no discurso. São Paulo: Contexto, 2008b, p. 119-137.

BARTHES, Roland. A paz cultural. In: O rumor da língua. São Paulo: Martins Fontes, 2004.

CANCLINI, Nestor Garcia. Culturas híbridas: estratégias para entrar e sair da modernidade. 2. ed. São Paulo, SP: Edusp, 1998.

Globalização imaginada. São Paulo: Iluminarias, 2004.

. Consumidores e cidadãos: conflitos multiculturais da globalização. 8. ed. Rio De Janeiro, RJ: UFRJ, 2010.

CHARAUDEAU, Patrick. Discurso das mídias. São Paulo: Contexto, 2009. 2008.

; MAINGUENAU, Dominique. Dicionário de análise do discurso. São Paulo: Contexto,

CHIZZOTTI, Antonio. Pesquisa qualitativa em ciências humanas e sociais. 3. ed. Petrópolis, RJ: VOZES, 2010

EXAME. Disponível em: <http://exame.abril.com.br/sobre/>. Acesso em: 07 nov. 2011.

FREITAS, Ernani Cesar de. FACIN, Débora. Semântica global e os planos constitutivos do discurso: a voz feminina na literatura de Rubem Fonseca. Desenredo - Revista do Programa de 
Pós-Graduação em Letras da Universidade de Passo Fundo, v. 7, n. 2, p. 198-218, jul./dez. 2011. Disponível em: < www.upf.br/seer/index.php/rd/article/download/2399/1552>. Acesso em: 12 maio 2012.

HALL, Stuart. A identidade cultural na pós-modernidade. 11. ed. Rio de Janeiro, RJ: DP\&A, 2006.

LARAIA, Roque de Barros. Cultura: um conceito antropológico. 14 ed. Rio de Janeiro: Zahar Ed., 2001.

MAINGUENEAU, Dominique. Novas tendências em análise de discurso . Campinas: 3. ed. São Paulo: Cortez, 1997.

. Análise de textos de comunicação. 3. ed. São Paulo: Cortez, 2002.

2008a.

Gênese dos discursos. Tradução de Sírio Possenti. São Paulo, SP: Parábola Editorial,

Cenas da enunciação. Organização de Sírio Possenti e Maria Cecilia Pérez de Souza-ESilva. São Paulo, SP: Parábola Editorial, 2008b.

.Ethos, cenografia, incorporação. In: AMOSSY, Ruth (Org.). Imagens de si no discurso. São Paulo: Contexto, 2008c, p. 69-91.

Doze conceitos em análise do discurso. Organização Sírio Possenti, Maria Ceília Perez de Souza e Silva; tradução Adail Sobral...[Et al.].São Paulo, SP: Parábola Editorial, 2010.

A propósito do Ethos. In: MOTTA, Ana Raquel; SALGADO, Luciana. Ethos discursivo. 2. ed. São Paulo: SP: Contexto, 2011, p. 11-32.

MATTA, Roberto da. O Que faz o Brasil, Brasil?. 12. ed. Rio de Janeiro: Rocco, 2001.

MORGAN, Gareth. Imagens da organização. 1. ed. São Paulo, SP: Atlas, 1996.

ORTIZ, Renato. Mundialização, cultura e política. In: DOWBOR, Ladislau; IANNI, Octávio; RESENDE, Paulo-Edgar (Orgs.). Desafios da globalização. Petrópolis, Vozes, 1997, p.260-279.

Mundialização e cultura. São Paulo: Brasiliense, 2007.

PETROBRAS. Nossa História. Disponível em: <http://www .petrobras.com.br/pt/quemsomos/nossa-historia/>. Acesso em: 25 maio, 2012

PRODANOV, Cleber Cristiano; FREITAS, Ernani César de. Metodologia do Trabalho Científico: métodos e técnicas da pesquisa e do trabalho acadêmico. Novo Hamburgo: Feevale, 2009.

SCHEIN, Edgar H. Cultura organizacional e liderança. Tradução Ailton Bomfim Brandão; revisão técnica Humberto Mariotti. São Paulo: Atlas, 2009.

SILVA, Edvania Gomes da. Os (des)encontros da fé: análise interdiscursiva de dois movimentos da Igreja Católica. Tese (doutorado). 293f. Universidade Estadual de Campinas: SP, 2006.

SOUZA-E-SILVA, Maria Cecília; ROCHA, Décio. Resenha de "Gênese dos discursos", de Dominique Maingueneau. ReVEL, v. 7, n. 13, 2009. Disponível em: <

http://www.revel.inf.br/files/resenhas/resenha.pdf>. Acesso em: 15 abr. 2012. 
VALE. Conheça a Vale. Disponível em: < http://www.vale.com.br/pt-br/conheca-avale/paginas/default.aspx>. Acesso em: 25 maio 2012.

ZAGO, Antonia; DI FANTI, Maria da Gloria. Palavras em operação: um dizer como trabalho, no trabalho e sobre o trabalho. Revista da ABRALIN, Universidade Federal do Rio Grande do Norte, v. 7, n. 1, p. 191-214, jan./jun. 2008. Disponível em: < http://www.abralin.org/revista/rv7n1/09Antonia-Zago.pdf>. Acesso em 14 abr2012

Original recebido em: $30 / 10 / 2012$

Aceito para publicação em: 20/11/2013

Sobre os autores

Andre Luciano Viana

Mestre em Processos e Manifestações Culturais na Universidade

Feevale. Especialista em Gestão Cultural e Bacharel em

Administração de Empresas.

Ernani Cesar de Freitas

Professor Doutor em Letras pela PUCRS, com pós-doutorado em Linguística Aplicada e Estudos da Linguagem (PUC-SP/LAEL). 